\title{
Shrinkage Curves for Powder and Granular Bentonites
}

\author{
Martin Wijaya ${ }^{1}$, Eng Choon Leong ${ }^{1, *}$, and Hossam Abuel-Naga ${ }^{2}$ \\ ${ }^{1}$ Nanyang Technological University, School of Civil and Environmental Engineering, 639798 50, Singapore \\ ${ }^{2}$ La Trobe University, Department of Civil Engineering and Physical Sciences, Melbourne, Australia
}

\begin{abstract}
Bentonite is one of the most commonly used materials in geotechnical engineering applications especially for isolation purposes due its low permeability and its highly expansive nature. For instance, Geosynthetic Clay Liners (GCL) self-healing ability relies on the swelling properties of the bentonite to close any holes in the GCL while the low permeability of the bentonite serves to reduce the infiltration of leachate to the surrounding soil. However, different types of bentonite have different shrinkage or swelling properties and hence affects the effectiveness of the GCL. A method to assess the wetting/drying induced volume change of the bentonite is through its shrinkage curve. This paper focuses on the shrinkage behaviour of reconstituted granular and powder bentonites which are used in GCL. Photogrammetry method is used to measure the volume change of specimen during drying. The shrinkage curves of the bentonites are then compared with other bentonites from the literature.
\end{abstract}

\section{Introduction}

Bentonite is a highly expansive, low permeability soil with wide applications. One of the applications is in geosynthetic clay liners (GCLs). In GCL, a thin layer of bentonite sandwiched between two layers of geotextile held together, generally by using needle punching. It is commonly employed as a low permeability barrier in waste disposal facilities to minimize the migration of leachate into the underlying soils and to the groundwater [1].

Geosynthetic clay liners are generally installed at the as-rolled gravimetric water content of 10 to $15 \%$ and then hydrated by allowing the bentonite to adsorb water from the underlying soils [2]. Hence, the gravimetric water content $(\mathrm{w})$ of the bentonite will vary during the installation and service periods. The restricted expansion of the bentonite in the GCLs as it adsorbs water under applied vertical stress is beneficial as it helps to reduce the pore spaces and the volume change due to drying [2]. To minimise spillage of the bentonite from the GCL, granular bentonite is commonly preferred compare to powder bentonite.

However, change in the volume of bentonite, due to the change in water content, will lead to a change in the permeability of the bentonite [3-5]. Thus, it is necessary to construct shrinkage curve to understand the relationship between water content with void ratio of the bentonite [6-8].

Shrinkage curve can be obtained by drying a soil specimen (i.e. air drying or drying in a desiccator under constant relative humidity) and recording the weight and volume of the soil specimen periodically [8]. The volume measurement can be done by simple methods such as direct measurement technique using a pair of
Vernier callipers or more advanced methods such as photogrammetry [8-10]. However, volume measurement based on direct measurement is limited to a soil specimen that has a simple geometry [10] which is not suitable for highly expansive soils such as bentonite due to the nonuniform volume change that causes the bentonite specimen to be highly distorted on drying. Moreover, bentonite at high water content is too soft for contact-based measurement as the measurement may induce disturbance to the specimen. Thus, photogrammetry is a one of the best techniques in measuring the volume of the bentonite specimen with reasonable accuracy $[9,10]$.

The shrinkage curve is commonly determined as a series of discrete data points. A shrinkage curve can be obtained by curve fitting the discrete data points using shrinkage curve equations. Shrinkage curve may have either 2,3 or 4 linear segments $[6,11-13]$. Thus, the curve fitting equation is selected according to the type of shrinkage curve. In order to use a single equation to fit any type of shrinkage curve, Leong and Wijaya [6] proposed a universal shrinkage curve equation:

$$
\begin{gathered}
e(w)=e_{\text {min }}+m_{1} w+\sum_{i=2}^{n} T_{i}\left(w, w_{i}, m_{i}, m_{i-1}, k_{i}\right) \\
T_{i}\left(w, w_{i}, m_{i}, m_{i-1}, k_{i}\right)= \\
\left(m_{i}-m_{i-1}\right) \frac{1}{2}\left\langle\mathrm{w}+\frac{1}{\mathrm{k}_{\mathrm{i}}} \ln \left\{\frac{\cosh \left[\mathrm{k}_{\mathrm{i}}\left(w-w_{\mathrm{i}}\right)\right]}{\cosh \left[\mathrm{k}_{\mathrm{i}} \mathrm{w}_{\mathrm{i}}\right]}\right\}\right\rangle \\
k_{i}=\frac{2}{w_{i+}-w_{i-}}
\end{gathered}
$$

\footnotetext{
* Corresponding author: cecleong $@$,ntu.edu.sg
} 
where $\mathrm{e}_{\min }$ is the minimum void ratio of the shrinkage curve, $m_{1}$ is the slope of the first segment of shrinkage curve which is usually equal to $0, \mathrm{~m}_{\mathrm{i}}$ is the slope of linear segment $\mathrm{i}, \mathrm{w}_{\mathrm{i}}$ is the water content at the intersection between linear segment $i$ and linear segment $\mathrm{i}-1$ and $\mathrm{k}_{\mathrm{i}}$ is the curvature parameters which can be determined either by using iteration or from $\mathrm{w}_{\mathrm{i}+}$ and $\mathrm{w}_{\mathrm{i}}$ which is defined as water content convergence point of linear segment $i$ and linear segment $i-1$, respectively. The physical definition of $\mathrm{w}_{\mathrm{i}}, \mathrm{w}_{\mathrm{i}-}$ and $\mathrm{w}_{\mathrm{i}+}$ for different types of shrinkage curve is given in Figure 1. As all of the parameters can be graphically obtained, optimization method is not required.

In this paper, the shrinkage curves of granular and powder bentonites are determined by photogrammetry method. The results are then compared with shrinkage curves of other bentonites from the literature.

\section{Experimental method}

The powder bentonite with liquid limit (LL) of $469 \%$ and granular sodium bentonite with LL of $294 \%$ were mixed (separately) with water until a homogeneous slurry was achieved. The slurry was then remoulded inside an oedometer specimen ring by applying net normal stress of about $500 \mathrm{kPa}$. The specimen was then extruded and then placed on a weighing balance in the setup described in Upreti and Leong [10]. However, glitter powder was sprinkled on the surface of the specimen as shown in Figure 2 to avoid the pin-cushion effect in the construction of the three-dimensional model (3D) in photogrammetry. Autodesk Recap Photo was used to combine 24 photographs taken at rotation intervals of $15^{\circ}$ around the specimen to construct the 3D model and MeshLab [16] is used to compute the volume of the 3D model.

When the soil specimen shrinks and distorts, the camera is unable to capture the bottom of the specimen which may not be planar when the shrinkage is large. Hence, when the soil specimen dries sufficiently to be handled, it was possible to place the specimen standing vertically on its edge to minimize the "hidden" part of the specimen as shown in Figure 3a. Figure $3 b$ shows the generated 3D model

\section{Bentonite shrinkage curves}

\subsection{Granular and powder bentonite}

Shrinkage curves of granular and powder bentonites are shown in Figures 4 and 5, respectively. Only data points at water content below $100 \%$ are shown as more emphasis is given to the part of the shrinkage curve that deviates from the saturation line. It is interesting to note that both bentonite specimens do not have zero shrinkage line, i.e., slope of shrinkage curve does not become zero. A number of researchers have also observed shrinkage curves which have no zero shrinkage line [13, 17-19]. Such shrinkage curves are classified as Type E [13]. The consequences of the absence of zero shrinkage line is that the granular and powder bentonite specimens do not have true shrinkage limit which defines the starting point of the zero shrinkage line.

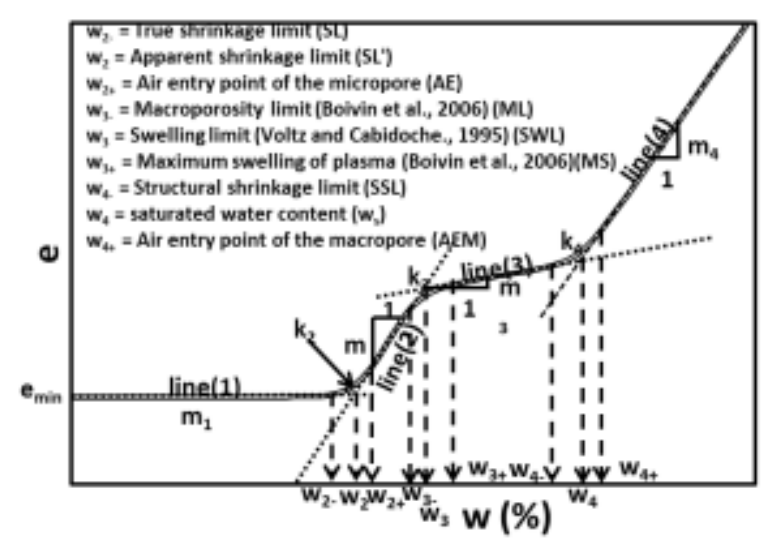

a) Four-linear segments shrinkage curve (types A and B).

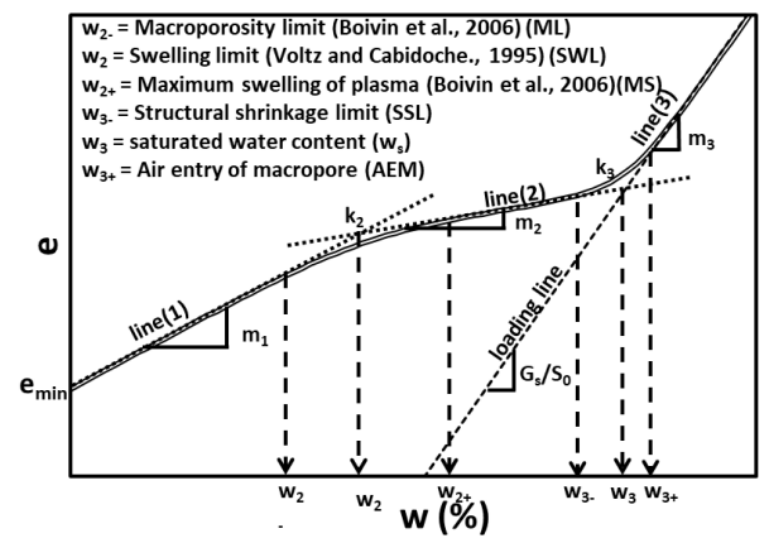

b) Three-linear segments shrinkage curve (types C and D).

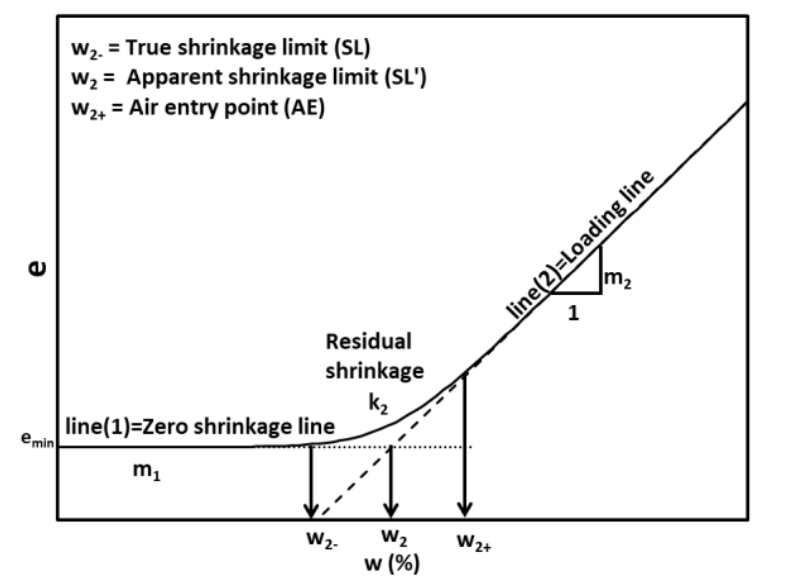

c) Two-linear segments shrinkage curve (types E and F).

Fig. 1. Type of shrinkage curve [6].

Shrinkage curve which has no zero shrinkage line can be modelled using Equation 1 with $\mathrm{m}_{1}$ set to be higher than zero. In Equation 1, the convergence point of the shrinkage curve with the first linear segment is referred to as the bentonite activation water content $\left(\mathrm{w}_{2-}\right)$ as the swelling rate starts to increase when the water content is higher than $\mathrm{w}_{2}$ - while the convergence point of the shrinkage curve with saturation line indicates the water content at air entry value $\left(\mathrm{w}_{2+}\right)$. Both $\mathrm{w}_{2-}$ and $\mathrm{w}_{2+}$ 
can be used to calculate the curvature parameter $\mathrm{k}_{2}$ by using Equation 1c. Thus, no optimization is required.

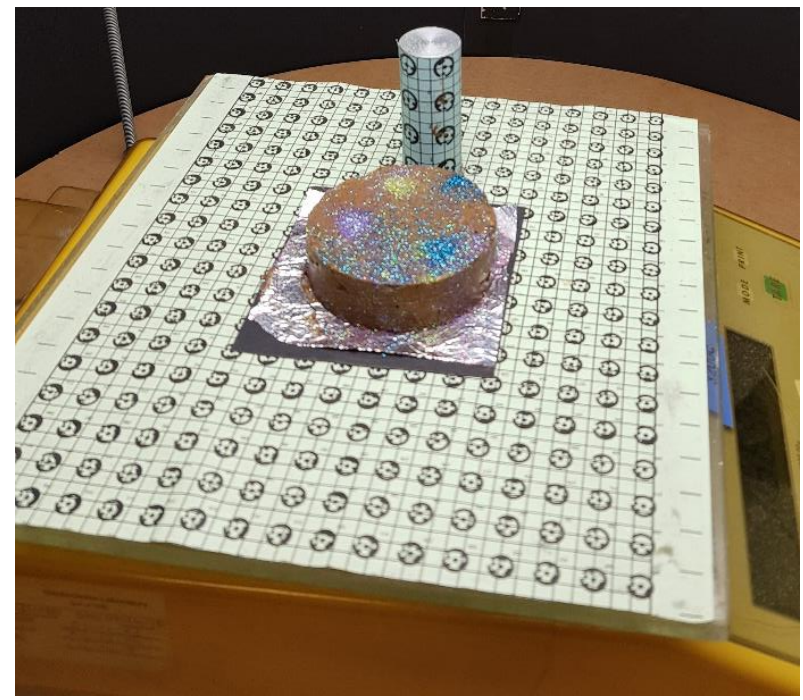

Fig. 2. Granular bentonite specimen at initial condition.

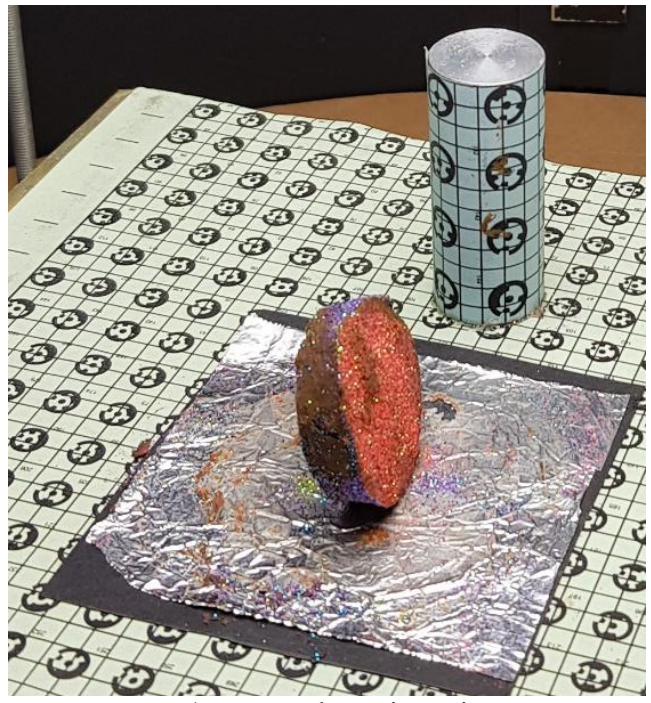

a) Actual specimen image

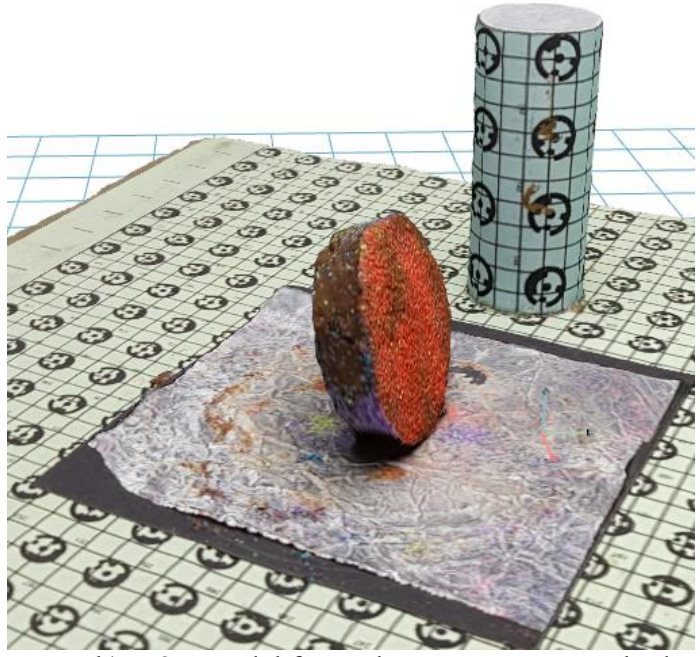

b) $3 \mathrm{D}$ model from Photogrammetry method

Fig. 3. Granular bentonite specimen after 10 days.

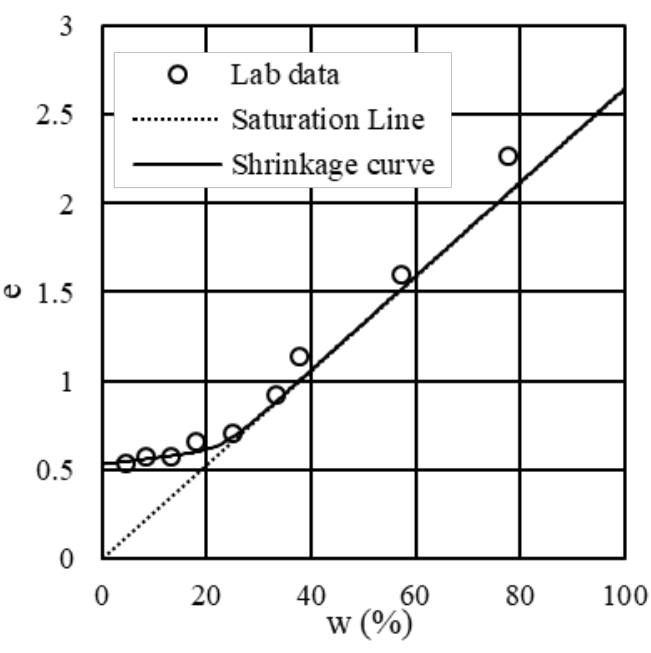

Fig. 4. Shrinkage curve of granular bentonite.

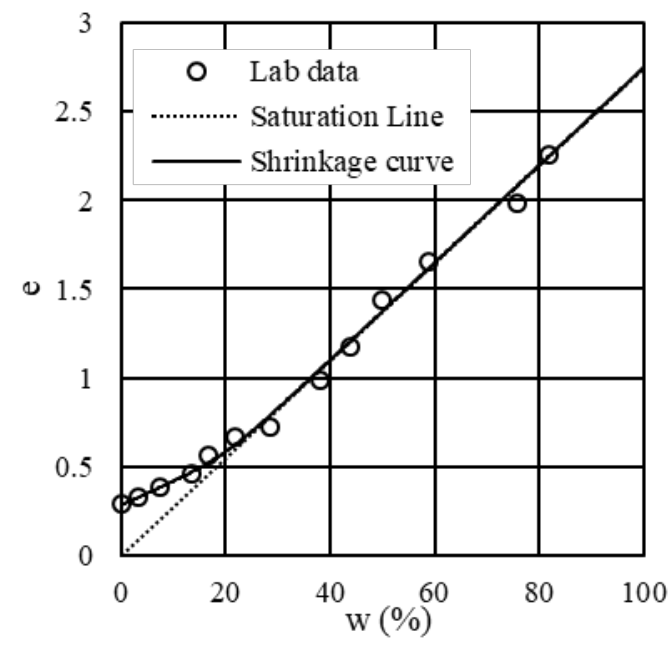

Fig. 5. Shrinkage curve of powder bentonite.

It is shown in Figures 4 and 5 that Equation 1 can be used to model shrinkage curve of bentonite which has no zero shrinkage line very well with $\mathrm{R}^{2}$ equals to 0.996 for granular bentonite and 0.995 for powder bentonite. Equation 1 parameters to construct the shrinkage curves of granular and powder bentonites are shown in Table 1.

Table 1. Shrinkage curve parameters for granular and powder bentonite.

\begin{tabular}{|c|c|c|c|c|c|}
\hline \multicolumn{6}{|c|}{ Granular Bentonite } \\
\hline$e_{\min }:$ & 0.528 & & & $\mathrm{R}^{2}:$ & 0.996 \\
\hline No. & $\mathrm{m}_{\mathrm{i}}$ & $\begin{array}{c}W_{i} \\
(\%)\end{array}$ & $\begin{array}{l}\mathrm{W}_{\mathrm{i}-} \\
(\%)\end{array}$ & $\begin{array}{c}\mathrm{W}_{\mathrm{i}+} \\
(\%)\end{array}$ & $\mathrm{ki}_{\mathrm{i}}$ \\
\hline 1 & 0.0037 & 0.00 & & & \\
\hline 2 & 0.0265 & 23.16 & 13.25 & 25.14 & 0.222 \\
\hline \multicolumn{6}{|c|}{ Powder Bentonite } \\
\hline $\mathrm{e}_{\min }:$ & 0.281 & & & $\mathrm{R}^{2}:$ & 0.995 \\
\hline No. & $\mathrm{m}_{\mathrm{i}}$ & $\begin{array}{c}\mathrm{W}_{\mathrm{i}} \\
(\%)\end{array}$ & $\begin{array}{l}\mathrm{W}_{\mathrm{i}-} \\
(\%)\end{array}$ & $\begin{array}{l}\mathrm{W}_{\mathrm{i}+} \\
(\%)\end{array}$ & $\mathrm{k}_{\mathrm{i}}$ \\
\hline 1 & 0.0132 & 0.00 & & & \\
\hline 2 & 0.0275 & 19.72 & 14.00 & 28.00 & 0.143 \\
\hline
\end{tabular}


The $\mathrm{w}_{2}$ for granular and powder bentonites are about $13 \%$ and $14 \%$, respectively, while $\mathrm{w}_{2+}$ for both granular and powder bentonites are about $25 \%$ and $28 \%$, respectively. Both $\mathrm{w}_{2-}$ and $\mathrm{w}_{2+}$ of the two bentonites are quite close. Precise determination of $\mathrm{w}_{2-}$ and $\mathrm{w}_{2+}$ are difficult due to insufficient data points. However, approximate determination is sufficient to give a high $\mathrm{R}^{2}$ value. Based on the value of $m_{1}$, the shrinkage rate of powder bentonite is 3.5 times that of the granular bentonite which leads to a lower value of $\mathrm{e}_{\min }$ for powder bentonite compare to granular bentonite.

\subsection{Bentonite-sand mixture [20]}

Agus and Schanz [20] investigated bentonite-sand mixture which was proposed to be used to seal radioactive waste canisters that will be buried in a deep geological repository in a saline environment. The LL of the bentonite-sand mixture is $130 \%$. The shrinkage curve constructed by using data from three specimens are shown in Figure 6. Figure 6 shows that the bentonitesand mixture experienced structural shrinkage. Table 2 shows that Equation 1 can fit the data very well with $\mathrm{R}^{2}$ equals to 0.999. Similar to granular and powder bentonites, the bentonite sand mixture does not a have zero shrinkage line. The $\mathrm{m}_{1}$ of the bentonite-sand mixture shrinkage curve is quite close to the $m_{1}$ of the powder bentonite shrinkage curve.

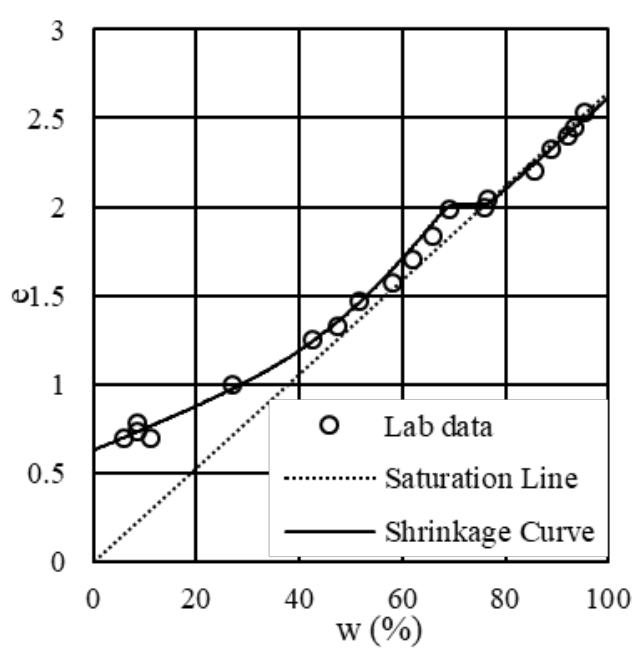

Fig. 6. Bentonite-sand mixture [20].

Table 2. Shrinkage curve parameters for Bentonite-sand mixture [20].

\begin{tabular}{cccccc}
\hline $\mathrm{e}_{\min }:$ & 0.628 & & & $\mathrm{R}^{2}:$ & 0.999 \\
\hline No. & $\mathrm{m}_{\mathrm{i}}$ & $\begin{array}{c}\mathrm{W}_{\mathrm{i}} \\
(\%)\end{array}$ & $\begin{array}{c}\mathrm{W}_{\mathrm{i}} \\
(\%)\end{array}$ & $\begin{array}{c}\mathrm{W}_{\mathrm{i}+} \\
(\%)\end{array}$ & $\mathrm{k}_{\mathrm{i}}$ \\
\hline 1 & 0.0120 & 0.00 & & & \\
2 & 0.0382 & 48.60 & 20.00 & 58.00 & 0.053 \\
3 & 0.0014 & 69.00 & 68.00 & 70.00 & 1.000 \\
4 & 0.0263 & 76.50 & 76.00 & 77.00 & 2.000 \\
\hline
\end{tabular}

\subsection{Denver bentonite [18]}

Lu and Dong [18] investigated the shrinkage curve of Denver bentonite with LL of $118 \%$. The shrinkage curve is shown in Figure 7. Similar with the other bentonites, it does not have zero shrinkage line and the structural shrinkage line is located somewhere between the shrinkage curve of granular and powder bentonites. However, the structural shrinkage of Denver bentonite is not as obvious as that of bentonite-sand mixture. Table 3 shows that Equation 1 can fit the data very well with $\mathrm{R}^{2}$ equals to 0.999 .

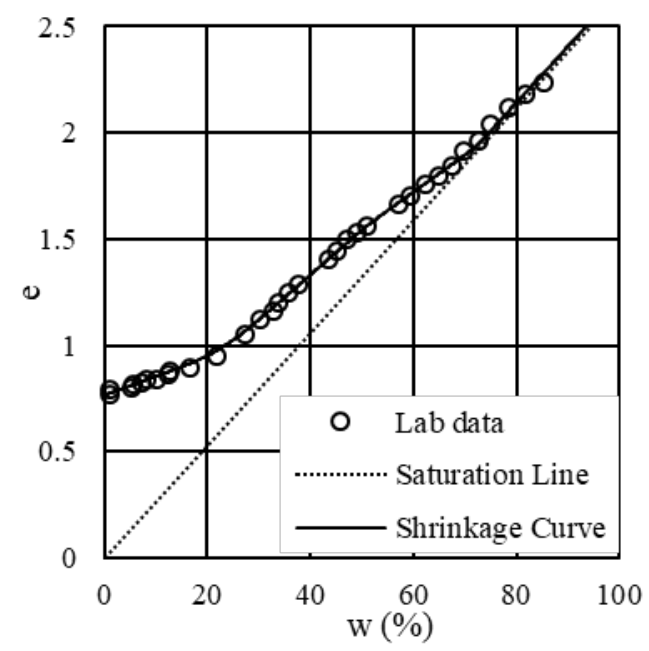

Fig. 7. Denver bentonite [21].

Table 3. Shrinkage curve parameters for Denver bentonite [18].

\begin{tabular}{cccccc}
\hline $\mathrm{e}_{\min }:$ & 0.765 & & & $\mathrm{R}^{2}:$ & 0.999 \\
\hline No. & $\mathrm{m}_{\mathrm{i}}$ & $\begin{array}{c}\mathrm{Wi}_{\mathrm{i}} \\
(\%)\end{array}$ & $\begin{array}{c}\mathrm{W}_{\mathrm{i}-} \\
(\%)\end{array}$ & $\begin{array}{c}\mathrm{W}_{\mathrm{i}+} \\
(\%)\end{array}$ & $\mathrm{c}_{\mathrm{i}}$ \\
\hline 1 & 0.0088 & 0.00 & & & \\
2 & 0.0212 & 22.81 & 16.60 & 27.17 & 0.189 \\
3 & 0.0174 & 51.00 & 50.94 & 57.00 & 0.330 \\
4 & 0.027 & 72.00 & 69.80 & 72.56 & 0.725 \\
\hline
\end{tabular}

\section{Conclusion}

In this paper, shrinkage curves of granular and powder bentonites have been constructed. In order to overcome the difficulties in measuring the volume of the bentonite specimen which becomes highly deformed during the drying stage, photogrammetry method was employed. Shrinkage curves of granular bentonite, powder bentonite, bentonite-sand mixture and Denver bentonite do not show a zero shrinkage line. It is shown that universal shrinkage curve equation proposed by Leong and Wijaya [6] can fit the shrinkage curves well. The minimum shrinkage void ratio of powder bentonite is smaller than that of granular bentonite. 


\section{References}

1. Q. A. Al Rashid, H. M. Abuel-Naga, E. C. Leong, Y. Lu, and H. Al Abadi, Applied Clay Science. 156. 1-10 (2018)

2. T. Özdamar Kul and A. H. Ören, Geotextiles and Geomembranes. 46(4). 436-447 (2018)

3. M. Wijaya and E. C. Leong, Canadian Geotechnical Journal. 1-3 (2018)

4. F. Zhang, G. W. Wilson, and D. G. Fredlund, Canadian Geotechnical Journal. 55(2). 191-207 (2018)

5. A. Bouazza, M. A. Ali, W. P. Gates, and R. K. Rowe, Geosynthetics International. 24(2). 139-150 (2017)

6. E. C. Leong and M. Wijaya, Geoderma. 237-238. 78-87 (2015)

7. M. D. Fredlund, G. W. Wilson, and D. G. Fredlund, in 3rd International Conference on Unsaturated Soils, UNSAT 2002. (2002): Recife, Brazil. p. 145149.

8. M. Wijaya, E. C. Leong, and H. Rahardjo, Soils and Foundations. 55(1). 166-180 (2015)

9. L. Li and X. Zhang, Geotechnical Testing Journal. 42(1) (2019)

10. K. Upreti and E. C. Leong, in PanAm Unsaturated Soils 2017. (2017).

11. M. Wijaya. Ph.D. Thesis, Civil and Environmental Engineering, Nanyang Technological University, Singapore. (2017)

12. M. Wijaya and E. C. Leong. in Softsoils 2014. Bandung (2014)

13. X. Peng and R. Horn, Soil Sci. Soc. Am. J. 77(2). 372-381 (2013)

14. P. Boivin, P. Garnier, and M. Vauclin, Soil Sci. Soc. Am. J. 70(4). 1082-1093 (2006)

15. Y. M. Cabidoche and M. Voltz, European Journal of Soil Science. 46(3). 345 (1995)

16. P. Cignoni, M. Callieri, M. Corsini, M. Dellepiane, F. Ganovelli, and G. Ranzuglia, in Sixth Eurographics Italian Chapter Conference. (2008). p. 129-136.

17. P. Chen and N. Lu, Journal of Geotechnical and Geoenvironmental Engineering. 144(8) (2018)

18. N. Lu and Y. Dong, Journal of Geotechnical and Geoenvironmental Engineering. 143(9) (2017)

19. E. C. Leong and M. Wijaya, ASCE's Journal of Geotechnical and Geoenvironmental Engineering, (2018)

20. S. S. Agus and T. Schanz, in Fourth International Conference on Unsaturated Soils. (2006), ASCE: Carefree, Arizona, United States.

21. M. Khorshidi and N. Lu, Journal of Geotechnical and Geoenvironmental Engineering. 143(4) (2017) 